Supporting Information

\title{
Mechanisms, Pathways and Dynamics of Excited-State Energy Flow in Self-Assembled Wheel-and-Spoke Light-Harvesting Architectures
}

\author{
Hee-eun Song, Christine Kirmaier, Lianhe Yu, \\ David F. Bocian, Jonathan S. Lindsey, and Dewey Holten
}

\section{Contents:}

(1) Titration data for the preparation of the $\mathbf{Z} \mathbf{n}_{\mathbf{6}} \bullet \mathbf{T P}$ complex.

(2) Titration data for the preparation of the $\mathbf{Z} \mathbf{n}_{6} \bullet \mathbf{D P F} \boldsymbol{b}$ complex.

(3) Transient absorption kinetic data for the $\mathbf{Z} \mathbf{n}_{6} \bullet \mathbf{D P F} \boldsymbol{b}$ complex.

\section{References:}

(1) Li, J.; Ambroise, A.; Yang, S. I.; Diers, J. R.; Seth, J.; Wack, C. R.; Bocian, D. F.; Holten, D.; Lindsey, J. S. J. Am. Chem. Soc. 1999, 121, 8927-8940.

(2) Ambroise, A.; Li, J.; Yu, L.; Lindsey, J. S. Org. Lett. 2000, 2, 2563-2566. 

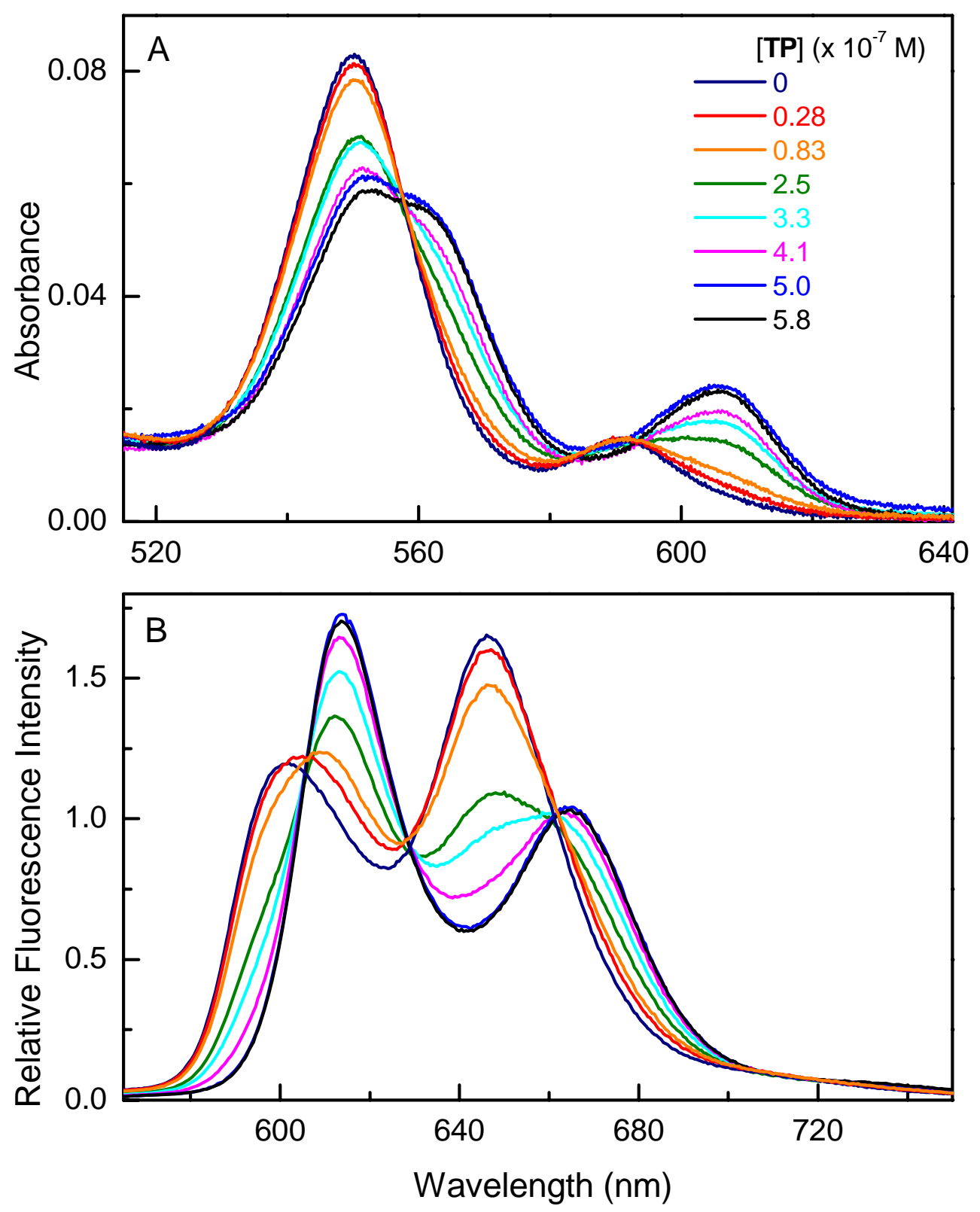

Figure S1. Absorption (A) and emission (B) spectra obtained for the formation of the $\mathbf{Z n}_{\mathbf{6}} \bullet \mathbf{T P}$ host-guest complex in toluene upon addition of the TP guest to the $\mathbf{Z n}_{6}$ cyclic hexamer host. The concentration of $\mathbf{Z n}_{6}$ is $4.1 \times 10^{-7} \mathrm{M}$ for all solutions. Emission spectra were obtained exciting at $550 \mathrm{~nm}$. Stock solutions of each component in toluene were prepared using the extinction coefficients for $\mathbf{Z n}_{6}$ in toluene (log $\varepsilon=6.43$ at $\left.429 \mathrm{~nm}\right)$ from ref 1 , and for $\mathbf{T P}$ in toluene (log $\varepsilon=$ 5.09 at $312 \mathrm{~nm}$ ) determined here. 

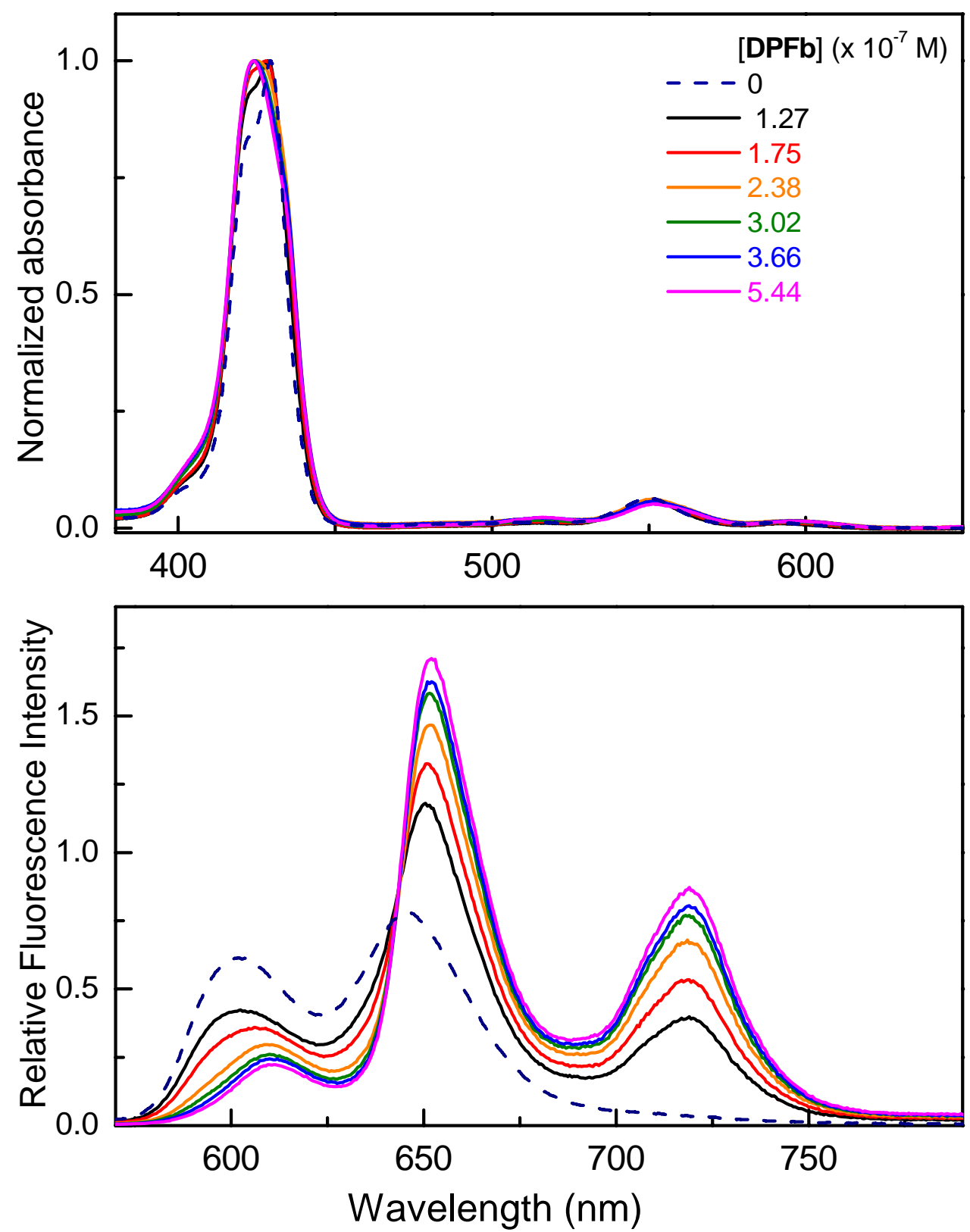

Figure S2. Absorption (A) and emission (B) spectra obtained for the formation of the $\mathbf{Z} \mathbf{n}_{\mathbf{6}} \bullet \mathbf{D P F} \boldsymbol{b}$ host-guest complex in toluene upon addition of the $\mathbf{D P F b}$ guest to the $\mathbf{Z} \mathbf{n}_{6}$ cyclic hexamer host. The concentration of $\mathbf{Z n}_{\mathbf{6}}$ is $2.3 \times 10^{-7} \mathbf{M}$ for all solutions. Emission spectra were excited at $550 \mathrm{~nm}$. Stock solutions of each component in toluene were prepared using the extinction coefficients for $\mathbf{Z n}_{\mathbf{6}}$ in toluene (log $\varepsilon=6.43$ at $429 \mathrm{~nm}$ ) from ref 1 , and for $\mathbf{D P F b}$ in toluene (log $\varepsilon=5.68$ at $422.6 \mathrm{~nm}$ ) given in Table 3 of the paper. 


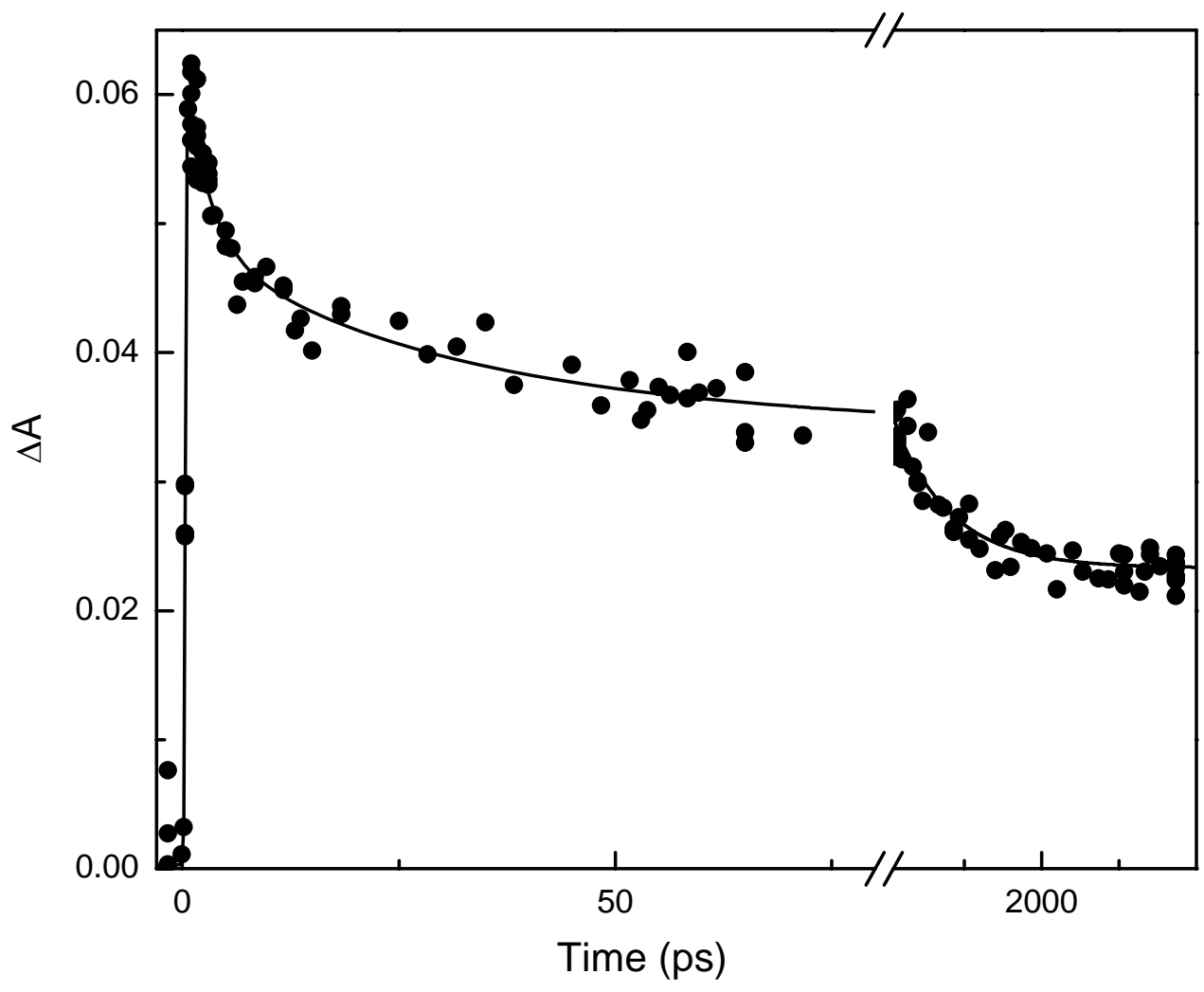

Figure S3. Kinetic data for the $\mathbf{Z n}_{6} \bullet \mathbf{D P F} \boldsymbol{b}$ host-guest complex in toluene measured at $630 \mathrm{~nm}$, following excitation with a $130 \mathrm{fs}$ flash at $532 \mathrm{~nm}$. The fit is for an instrument response plus three exponentials plus a constant. The average time constants from this wavelength and data spanning 570 to $760 \mathrm{~nm}$ are of $3.1 \pm 0.7 \mathrm{ps}, 33 \pm 9$ ps, and $730 \pm 80$ ps. 